\title{
Pemphigus and steroid psychosis: a case report and review of literature
}

\author{
K. Beqqal ${ }^{1,2}$, E. Chau ${ }^{2}$, K. Senouci ${ }^{1}$, W. Ouahid ${ }^{3}$, L. Benzekri ${ }^{1}$, B. Hassam ${ }^{1}$, Fz. Belgnaoui ${ }^{1}$ \\ 1. Dermatology department, Centre Hospitalier Universitaire Ibn Sina Rabat, Université Souissi Rabat. Morocco. \\ 2. Dermatology department, APHP Cochin-Tarnier, Université Paris Descartes, Paris, France. 3. Psychiatric department, \\ Hôpital Arrazi Salé, CHU I bn Sina, Université Souissi, Rabat, Morocco.
}

Correspondence: Kawtar Beqqal. Address: Impasse Oualidia, résidence yasmina, appt 14, avenue MED V, Rabat, Morocco. E-mail: kawtarbeqqal@yahoo.fr

Received: February 9, 2014

DOI : $10.5430 /$ crcp.v1n2p101

Online Published: May 14, 2014

Accepted: April 30, 2014

Online

\section{Abstract}

Oral corticosteroid therapy is commonly prescripted in dermatology. Psychiatric side effects are often underestimated and symptoms are not specific. We report a case of a 64 year old man, with no significant history, presented with Pemphigus lesions. Psychosis symptoms and steroid psychosis occurred within five weeks after initiating of corticosteroid therapy.

\section{Key words}

Pemphigus, Oral corticosteroids, Confusion, Mood disorders

\section{I ntroduction}

Oral corticosteroid therapy is communely prescripted for skin diseases with high posology and often for a long term.

Metabolic and organic side effects of steroid therapy are well known to physicians; osteoporosis, diabetes, high blood pressure. However, psychiatric side effects are often underestimated and misknown because of no specific symptoms.

\section{Case report}

A 64 year old man, with no significant history, presented with skin bullous lesions and oral erosions evolving for three months. The diagnosis of Pemphigus was made on clinical lesions according to histological and immunological findings. Corticosteroid therapy was started at $130 \mathrm{mg}$ daily with a posology of $2 \mathrm{mg} / \mathrm{kg} / \mathrm{day}$.

Three weeks later, the patient reported decreased sleep, increased energy, pressured speech and increased appetite. He said that he feels energetic even if he has insomnia episodes. Evolution of psychiatric was so rapid. The 4th week, he had altercations with the medical staff and appeared disinhibited and aggressive, attacking on one occasion a nurse.

The 5th week of corticosteroid treatment, he became more aggressive and confused with depressive mood with loss of appetite and need to be alone. He reported also distorsion body image. He said that "I have lost one leg and I am not able to 
stand up”. He had also cognitive symptoms with verbal and visual memory disorders and disorientation. He did recognize neither his doctors nor his family.

A psychiatric opinion was requested and the diagnosis of steroid psychosis was made. A psycho-organic origin was excluded. Serological tests including blood profile, electrolytes, liver function tests and thyroid functions was normal as well as radiological investigations; cerebral scan and EEG were also normal.

According to DSM V criteria's, substance-Induced Mood Disorder is characterized by a prominent and persistent disturbance in mood that is judged to be a direct physiological consequence of a drug of abuse, a medication, another somatic treatment for depression, or toxin exposure.

The psychiatric disorders were so related to corticosteroids. Improvement of mood disorders occurred within two weeks of psychotic treatment; Laroxyl ${ }^{\circledR} 40$ drops/day and anxiolytics Atarax ${ }^{\circledR} 100$ mg: 2 tablets/d in association to a rapid reduction of corticosteroids doses.

The dermatological and psychiatric follow up was regular. Three months later, the patient recovered all psychiatric functions with a complete remission of Pemphigus.

\section{Discussion}

Psychiatric disorders during corticosteroid is poorly understood and often underestimated. Symptoms are not specific and included mood, psychotic and cognitive disorders ${ }^{[1]}$.

These disorders seem to be related to hippocampal dysfunction because of high concentration of glucocorticoid receptors of the hippocampe ${ }^{[2]}$.

Mood disorders are more frequent type mood swings, mania access (increased energy, decreased sleep, agitation, and rapid speech), depressive mood or bipolar disorder ${ }^{[1]}$. Mania symptoms are more common during short courses of high dose steroids and depression symptoms in long term steroid treatment ${ }^{[2-4]}$.

Psychotic symptoms might be serious including suicidal ideation. Hallucinations, delusional beliefs, disorganized thought processes and distorsion of body image are reported ${ }^{[2,5]}$. Cognitive symptoms are also described; Brown et al. ${ }^{[5]}$ studied effects of corticosteroids on memory and concluded to cognitive impairment, with dementia and delirium. Our patient presented with severe form of psychiatric steroid induced symptoms.

Sirosis ${ }^{[3]}$ classified severity of steroid psychosis into three levels: euphoria sub-clinical and non-pathological, mood disorders, and psychosis and dementia.

Steroid psychiatric symptoms are dose dependent ${ }^{[7-9]}$. Boston collaborative drug surveillance program concluded that the risk of developing severe psychiatric illness increased by $18.4 \%$ when doses greater than $80 \mathrm{mg} /$ day were administrated ${ }^{[7]}$.

Patients at high risk are those with a history of psychiatric disorders, or monitored for endocrine or systemic disease. Age and gender are not significant factors ${ }^{[9-11]}$.

Mean average onset symptoms range from 2 to 5 weeks from starting corticosteroids. The case of our patient joins the data from the literature ${ }^{[3,8,9]}$. Sometimes, symptoms may occurred within the first week; Naber et al. reported psychiatric symptoms in 50 patients free of psychiatric illness treated for ophthalmologic diseases (uveitis, retinitis) at mean doses $119 \mathrm{mg} /$ day of prednisolone for only eight days. 
Prevalence of psychotic disorders in dermatological diseases is misknown. Few studies has been reported and only two reports studied prevalence of psychosis in bullous skin diseases by literature screening with Medline, Sciences-direct and Inist databases.

Picardi et al. ${ }^{[6]}$ studied psychiatric morbidity among 592 dermatological patients. The prevalence ranges from $21 \%$ to 43\%. Patients was aged 30-39 in 25, 7\% and less than 30 year old in 27,6\%. Fifty one percent of these patients had education Senior high school $51 \%$ and was treated for various skin diseases: Psoriasis $28 \%$, dermatitis $10 \%$, connective tissue diseases $6.7 \%$, skin ulcers $3.6 \%$, bullous disease $3.8 \%$ and skin cancers $4.6 \%$.

Psychiatric diagnoses were depressive disorder (19.8\%), anxiety disorder (15.4\%), adjustment disorder (7.1\%) and somatoform disorder (6.1\%).

Recently, in the Iranian study (Arbabi et al. 2008) ${ }^{[11]}$, this prevalence was $51.3 \%$ and high rates observed among patients with vitiligo, psoriasis and Pemphigus.

Psychiatric symptoms are reversible. Discontinuation or reduction of steroid doses improves symptoms. Valproic acid, neuroleptics, antipyschotics, olanzapine, fluoxetine are useful and improved psychiatric disorders. Lithium can be prescripted to patients with risk factors and seems to be useful to prevent symptoms ${ }^{[8-12,15]}$.

Hall and al reported that tricyclic antidepressants can lead to a significant worsening of symptoms ${ }^{[12]}$ and so might be avoided.

Drug interaction during corticosteroid therapy should be known. Prednisolone-clarithromycin interaction leads to increase corticosteroids plasma levels by inhibiting cytochrome systems ${ }^{[13,14]}$.

Therefore, recognizing psychiatric disorders by regular evaluation of mood or behaviour changes as monitoring glucose or blood pressure, informing patients who start oral steroid therapy of potential psychiatric side effects anda collaboration between dermatologists and psychiatrists will serve effectively to management and prevention of steroid psychosis.

\section{Conclusion}

Use of high corticosteroid doses in dermatology diseases treatment is common. Prevalence of psychiatric steroid induced symptoms in dermatology seems to be frequent in daily dermatological practice. However, this prevalence is misknown and often underestimated as symptoms are not specific.

Psychiatric disorders are steroid dose dependent, including mood, psychotic and cognitive disorders. Sometimes, steroid side effects might be severe as our case report. Therefore, it is important to physicians to recognize these disorders.

\section{References}

[1] Brown ES, Khan DA, Nejtek VA. The psychiatric side effects of corticosteroids. Ann All Asthimmune. 1999; 83: 495-9. http://dx.doi.org/10.1016/S1081-1206(10)62858-X

[2] Brown ES, Rush AJ, et al. Hippocampal remodeling and damage by corticosteroids: complications for mood disorders. Neuropsuychopharmacology. 1999; 21: 474-84. http://dx.doi.org/10.1016/S0893-133X(99)00054-8

[3] Sirosis F. Steroid psychosis: a review Gen Hosp Psych. 2003; 25: 27-33.

[4] Naber D, Sand P, Heigl B. Psychological and neuropsychological effects of 8days'corticosteroid treatment: a prospective study. Psychoneuroendocrinology. 1996; 21: 25-31. http://dx.doi.org/10.1016/0306-4530(95)00031-3

[5] Brown ES, Chandler P. Mood and cognitive changes during systemic corticosteroid therapy. J Clin Psychiatry. 2001; 3: 17-21. 
[6] Picardo A, et al. Screening for psychiatric disorders in patients with skin diseases. J psychosom Res. 2004; 57: 219-23. http://dx.doi.org/10.1016/S0022-3999(03)00619-6

[7] The boston collaborative drug surveillance program. Acute adverse reactions to prednison in relation to dosage. Clinpharmacolther. 1972; 13: 694-8. PMid: 5053810.

[8] Newcomer JW, Selke G, Melson AJ, et al. Decreased memory performance in healthy humans induced by stress-level cortisol treatment. Arch gen psychiatry. 1999; 56: 527-33. PMid: 10359467. http://dx.doi.org/10.1001/archpsyc.56.6.527

[9] Lewis DA, Smith RE. Steroid induced psychiatric diseases: a report of 14 cases and a review of litterature. J Affect Disord. 1983; 5: 319-32. http://dx.doi.org/10.1016/0165-0327(83)90022-8

[10] Stoudemire A, Anfinson T, Edwards J. Corticosteroid-induced delirium and dependency. Gen hosp psychiatry. $1996 ; 18: 196-202$. http://dx.doi.org/10.1016/0163-8343(96)00005-9

[11] Arbabi M, Ghaninejad H, Samadi Z, Golestan B, Parsafar H. Psychiatric comorbidies in dermatology patients in Iran. EACLPP abstracts. J Psychosom Res. 2008; 636-7.

[12] Hall RCW, Popkin MK, Stickney RN, Gardner E. Presentation of the steroid psychosis. Jnervment dis. 1979; 167: 229-36. PMid: 438794. http://dx.doi.org/10.1097/00005053-197904000-00006

[13] Folks DG. Screening for psychiatric disorders in patients with skin diseases. J psychosom Res. 2004; 57: 225-6. http://dx.doi.org/10.1016/S0022-3999(04)00452-0

[14] Westberg L, Eriksson E. Sex steroid-related candidate genes in psychiatric disorders. J psychiatry neurosc. 2008; 33: 319-30.

[15] Rome HP, Braceland FJ. Use of cortisone and acne in certain diseases. Psychiatric aspects. Proc staff meet mayo clinic. 1950; 25: 495-7. PMid: 15440932. 